\title{
Experiences of Stigma and Discrimination among Adults Living with HIV in a Low HIV-Prevalence Context: A Qualitative Analysis
}

\author{
Ann P. Zukoski, Dr.P.H., M.P.H. and Sheryl Thorburn, Ph.D., M.P.H.
}

\begin{abstract}
Little is known about how people living with HIV in low prevalence contexts face the challenges of stigma and discrimination. Low prevalence and rural communities are unique environments in which HIV-related stigma and discrimination may be intensified due to lower tolerance of differences among people and greater fear of HIV. This study examined the experiences of 16 individuals living with HIV who reside in a predominantly rural area with low HIV prevalence. We used in-depth interviews to explore participants' experience with stigma and discrimination in social and health care settings and their behavioral and emotional responses. In their day-today lives, participants described feeling social rejection, being forced to follow different rules of social contact, and being treated differently. In health care settings, participants described specific instances when they felt providers were afraid of them and when they were refused or discouraged treatment or treated differently based on their HIV status. Participants experienced stigma and acts of discrimination in different settings (e.g., physician and dentist offices and hospitals) and from a range of types of providers (e.g., physicians, nurses, and dentists). Behavioral and emotional responses to perceived acts of stigma and discrimination included anger, shame, social isolation, and self-advocacy. Findings point to a need to develop tailored interventions to address stigma and discrimination for individuals, health care personnel and the community-at-large.
\end{abstract}

\section{Introduction}

$\mathbf{H}$ IV/AIDS REMAINS THE MOST HIGHLY stigmatized illness in the United States, profoundly affecting the lives of individuals living with HIV. As a socially constructed process, HIV-related stigma results in prejudice and acts of discrimination toward individuals living with HIV. Both stigma and discrimination are associated with negative health outcomes for people living with HIV including poor antiretroviral therapy adherence, ${ }^{1-3}$ engagement in unsafe sexual behaviors, ${ }^{4}$ increased levels of depression ${ }^{3,5-8}$ higher levels of posttraumatic stress symptoms, greater severity of AIDSrelated symptoms, lower perceived general health, and less health care satisfaction. ${ }^{3}$

The majority of the research on stigma and discrimination to date has focused on populations living in high HIV prevalence areas concentrated in urban locations. ${ }^{1-8}$ Despite the fact that large numbers of people living with HIV and AIDS in the United States are distributed across metropolitan and nonmetropolitan regions with low prevalence of $\mathrm{HIV},{ }^{9}$ there is limited information about how stigma manifests itself within these regions including more socially isolated areas such as rural communities. The Centers for Disease Control and Prevention (CDC) reports that $46 \%$ of AIDS cases reported in the United States through 2006 were dispersed across 40 states with annual AIDS rates below the annual rate for the United States (12.7 per 100,000 in 2006). ${ }^{10}$ Through 2005, more than 48,000 persons diagnosed with AIDS were living in nonmetropolitan statistical areas (MSAs) (population $<50,000$ ) and an additional 83,372 were living in metropolitan statistical areas with populations between 50,000 and $500,000 .{ }^{11}$ AIDS case rates also vary considerably based on community size. For example, in 2005 AIDS case rates were 6.4 per 100,000 for non-metropolitan areas compared to 9.3 per 100,000 in areas with populations between 50,000-500,000 and 21.1 per 100,000 for MSAs with populations of greater than $500,000 .^{11}$

Low prevalence and rural contexts present unique environments where people living with HIV/AIDS are more likely to reside in socially isolated conditions and have fewer resources at their disposal. ${ }^{12,13}$ Stigma may be intensified in these areas where there is less tolerance of diverse lifestyles,

Department of Public Health, Oregon State University, Corvalis, Oregon. 
greater fear of HIV, and less anonymity. ${ }^{14-16}$ In addition, unlike high prevalence or urban areas with high rates of HIV, low prevalence areas have fewer medical experts, have limited social support programs, and lack comprehensive AIDS services, which alter people's experiences. ${ }^{17-19}$ Support services provided by the Ryan White Care Act, including case managers and funds to support transportation to doctor visits, dental care and associate services, are limited in low prevalence areas due to a funding allocation method, which is based on number of AIDS cases diagnosed in a given county. ${ }^{20}$ In addition, rural regions in particular are affected by inadequate health infrastructure, underfunded rural health and social services programs, higher poverty, geographic challenges and a higher proportion of people who lack health insurance. ${ }^{13,21-23}$

The handful of HIV-related stigma and discrimination studies conducted in rural areas suggests that social context matters. In a study comparing urban and rural people living with HIV/AIDS, Heckman et al. ${ }^{24}$ found that rural people living with HIV, compared to their urban counterparts, reported significantly lower satisfaction with life, lower perceptions of social support from family members and friends, reduced access to medical and mental health care, elevated levels of loneliness, more community stigma, and heightened personal fear. In a study of people living with HIV in rural areas taking antiretroviral therapy, participants reported they skipped doses of medication to avoid the stigma associated with publicly taking medication that could disclose their HIV status. ${ }^{25}$ Negative attitudes of rural health care providers also may impact people living with HIV who seek care in these areas. Discrimination in care and unwillingness to care for people living with HIV/AIDS has been found among physicians, ${ }^{26}$ dentists, ${ }^{27}$ and rural nurses. ${ }^{28}$ In a recent study of HIV service professionals from rural areas in the midwestern part of the United States, providers reported stigma and discrimination perpetrated by other medical staff and physicians as a major barrier their clients face when referred for medical services. ${ }^{29}$ Thus people living with HIV in low prevalence and rural areas appear to experience challenges that can intensify the impact of stigma.

A small number of qualitative studies have examined patients experiences with HIV stigma and discrimination in health care settings but these have focused on urban samples. ${ }^{30-32}$ One study examined stigma among groups of women living in New York City diagnosed with HIV prior to the introduction of highly active antiretroviral therapy (HAART) and post-HAART, finding that women in the pre-HAART group experienced enacted stigmatization more frequently and intensely and were more likely to have been verbally offended and discriminated against by family, friends and professionals than post-HAART participants. ${ }^{30}$ Another study of veterans living with HIV in a large metropolitan city identified subtle forms of stigma and discrimination that occur during health care visits and found that stigma took on a variety of forms and ranged from ambiguous nonverbal cues to blatant discriminatory acts across different types of health care personnel. ${ }^{31}$ In a qualitative study of a diverse group of low-income men and women living with HIV in Los Angeles, California, Sayles et al. ${ }^{32}$ found that participants faced stigma in medical settings but less commonly in HIV specialty care clinics. Although findings from these studies provide insight into problems and issues related to stigma and discrimination that individuals living with HIV face, there is a gap in understanding how these same issues impact individuals living with HIV in rural or low HIV prevalence settings.

Although studies of stigma, prejudice, and discrimination derive from different research traditions, each seeks to understand how individual experiences, interpersonal interactions between marginalized and nonmarginalized groups, and broader structural and social phenomena such as power and community practices impact individual health. ${ }^{33-35}$ In a recent conceptual review, Stuber et al. $^{35}$ argue that studying the impact of stigma, prejudice, and discrimination will help improve understanding of how these experiences contribute to psychosocial stress and health outcomes of marginalized groups. HIV stigma has been defined to include prejudice, discounting, discrediting, and discrimination directed at people perceived to have AIDS or HIV. ${ }^{36}$ In this paper, the term "stigma" is used to refer to this broader set of attitudes, beliefs, and behavior, and "discrimination" is used to refer more specifically to prejudicial behavior or negative treatment. Specific aspects and dimensions of stigma and discrimination can be difficult to identify, quantify, and describe because of their subtle, nebulous, and unnamed nature, and because stigma and discrimination can take on different forms in different environments. The purpose of this study is to contextualize and describe how people living with HIV in a predominantly rural area with low rates of HIV/AIDS experience and respond to perceived acts of stigmatization and discrimination in their day-to-day lives and in health care settings.

\section{Methods \\ Study context}

This study was conducted in a three-county area in Oregon. The area is predominately rural and includes cities with populations no larger than 60,000 . Oregon is one of 31 states with an annual AIDS rate below 10.0 per 100,000 in $2006 .{ }^{10}$ Similar to other rural HIV care delivery systems, ${ }^{37}$ one physician serves as the primary health care provider for the majority of people living with HIV/AIDS in the area. In addition, each county health department has a part-time Ryan White case manager who is responsible for ensuring that eligible clients have access to medical care, medications and drug treatments, and essential support services. ${ }^{38}$

\section{Participants and procedures}

Participants were adults living with HIV residing in the three-county area described above. To be eligible for the study, participants had to self-report being HIV positive and be age 18 years or older. The primary recruitment source was a local physician who is the primary medical provider for persons diagnosed with HIV living in the three targeted counties. Four of the 16 participants were recruited through the physician as key informants to pilot the interview guide and obtain feedback on interview questions. Ten of the remaining participants were recruited by flyers distributed by the physician to patients during their regularly scheduled appointments. The final two interviews were conducted after efforts to recruit were expanded to include the distribution of flyers by one other local physician who provides care for a much smaller number of HIV patients and by case managers 
at two local health departments. The flyer provided basic information about the study including the project's toll free number. Interested persons phoned the project's number; a recorded greeting instructed them to leave a message. They were then contacted by project staff, screened for eligibility, and scheduled for interviews. Sixteen face-to-face interviews were conducted between October 2005 and June 2006. Fourteen of the participants resided in the targeted three-county area, and two resided in an adjacent county. Interviews were conducted in private rooms in public locations such as libraries. The first author conducted three of the key informant interviews. Trained interviewers conducted the rest of the interviews. Written informed consent was obtained from all participants before they were interviewed. All interviews were audiotaped. Interviews were designed to take approximately 60 minutes to complete. Participants received a $\$ 25 \mathrm{gift}$ card as compensation for their time. This study was approved by the Oregon State University Institutional Review Board.

\section{Interview guide}

The interview guide included predominately open-ended questions and probes. The development of the interview guide was an iterative process: during and after the initial key informant interviews, questions were added, revised, or dropped based on information gleaned during the interview process. The final guide consisted of 22 main questions, as well as several follow-up questions and a series of probes. Topics covered included stigma, trust and mistrust of health care providers, discrimination when getting health care, and health literacy. Questions were also included to better understand the community context of HIV (e.g., barriers to treatment, what it is like to be HIV positive in the community). In addition, structured questions to collect sociodemographic and health history data were included at the end of the interview guide. For this study, we were particularly interested in perceptions and experiences related to stigma and discrimination.

\section{Data analysis}

Audiotapes of the interviews were transcribed. Data were analyzed using content analysis techniques. ${ }^{39}$ First, the authors independently read the complete transcripts and generated a list of codes focusing on the main topics. They then discussed the codes and jointly developed a refined list of codes for major topics and themes. Next, they independently coded the transcripts. The authors then met and reviewed the transcripts page by page and compared coding of the text. For this paper, the analysis focused on text related to participant's recent experiences with stigma and discrimination. There were no major inconsistencies in coding; minor differences were discussed and resolved. The final step was to summarize the results derived from the analysis and select verbatim quotations to illustrate each theme.

\section{Results}

\section{Participant characteristics}

Participants were diverse in terms of most of the measured sociodemographic characteristics. Nine were men, and seven were women. Thirteen participants were white, one was Native American, and two reported being of mixed heritage (Native American and white, Latino and white). Three participants were aged 18-34, six were aged 35-49, and seven were 50 or older. Ten lived alone, and the remainder lived with other people. Ten participants reported completing or attending some college or technical school, four were high school graduates, one completed some high school, and one had less than a high school education. Two participants worked full-time and one part-time, five were unemployed, six were on disability, and two were retired and on disability. Two participants reported they were students.

With regards to their HIV diagnosis and status, most $(n=14)$ reported visiting a health provider for treatment within 3 months of testing positive for HIV. At the time of the interview, 7 participants reported having had HIV for 5 or more years, 6 for 10 or more years and 2 reported having HIV for less than 1 year $(1$ missing). Only 5 participants reported being hospitalized in the last year. Nine of the 16 participants said they had been diagnosed with AIDS. Participants identified their HIV risk group as current or former injection drug use $(n=2)$, unprotected homosexual intercourse $(n=7)$, unprotected heterosexual intercourse $(n=3)$, and blood transfusion $(n=1)$; some reported more than one risk group $(n=3)$. Four participants rated their health as excellent, three as very good, three good, three fair, and three reported their general health as poor (Table 1 and 2).

\section{Stigma and discrimination in the community}

A specific aim of this study was to identify how people living with HIV experienced stigma in their day-to-day activities living in a low HIV prevalence community. All

Table 1. Sample Demographics $(n=16)$

\begin{tabular}{lr}
\hline Gender & 7 \\
Female & 9 \\
Male & \\
Race/Ethnicity & 13 \\
White/Caucasian & 1 \\
Native American & 1 \\
Native American and White & 1 \\
Latino/White & \\
Age & 3 \\
18-34 & 6 \\
35-49 & 7 \\
Z50 & \\
Live alone or with people & 10 \\
Alone & 6 \\
With others & 7 \\
Have children & 7 \\
Yes & 2 \\
No & \\
Missing data & 1 \\
Education completed & 1 \\
Elementary & 4 \\
Some high school & 10 \\
High school graduate & \\
Some or completed college or technical & 1 \\
Employment Status & 2 \\
Part-time & 5 \\
Full-time & 6 \\
Unemployed & 2 \\
Disability & \\
Retired and disability & \\
\hline
\end{tabular}


Table 2. Sample HIV/AIDS Related Characteristics $(n=16)$

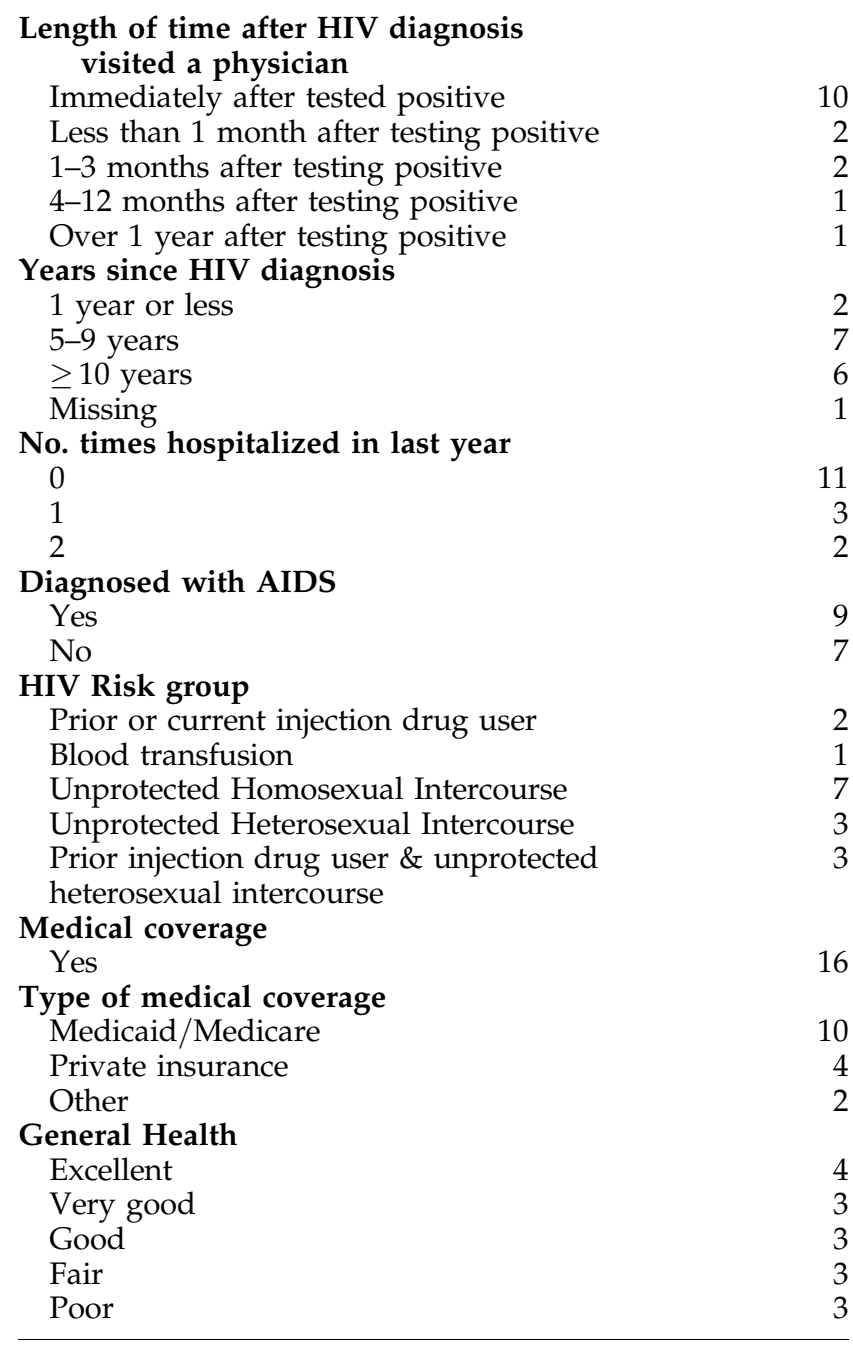

participants discussed the presence of HIV-related stigma in their communities. Fourteen reported personal experiences with stigma due to their HIV status. Two respondents reported that they had not personally experienced stigma but were aware that others did.

Three main themes related to stigma and discrimination emerged from the data. Social rejection from friends and family was the main form of stigma described. Rejection included loss of friends and being asked to take precautions around loved ones. Second, participants reported being asked to follow specific rules because of their HIV status. Third, participants described being treated differently because of their seropositive status in subtle and direct ways. Participants also described experiencing being treated differently due to the costigma of being both HIV positive and gay or an injection drug user.

Social rejection. Participants described being rejected by friends, family, and people in different social settings because of their HIV status. One participant described it this way,

... just a couple of weeks ago I ran into an old friend of mine I haven't seen in a couple of years and we were catching up and I told her I was HIV + and the expression on her face almost made me ill. It was kind of like, Eeww you're standing this close to me? I was like, oh [expletive].... -man, age 20

Another example is from a participant who described being rejected while in a drug recovery program, as illustrated in the following quote:

... when they wouldn't hold my hand during the final prayer, that upset me, there's lots of people like that, won't hold my hand, won't touch me and don't want me to pick up their babies and that kind of stuff. — woman, age 54

Rules of social contact. Others described that friends and family set up rules for social contact. Rules were made to limit interactions among friends or family members based on fear of spreading HIV to loved ones. As two participants indicated:

... I have one friend who I grew up with. . he was at my house and I was showing him my (jet ski) and I said "We'll have to go take the (jet skis) out" and he goes, "We can but my wife and child couldn't because...". I don't know why, but he just said because they couldn't do that. And I've known this guy my whole life. . . and it just kind of floored me. I didn't say anything to him, I just said ok. . He left and stuff and I thought [expletive] you. . . - man, age 50

... Some of my grandkids. . I'm not allowed to have any (contact). That's really frustrating because I am not going to have sex with them or bleed all over them or anything like that. So, they're just ignorant. . . -woman, age 52

Treated differently. Stigma also manifested itself as people treating participants differently because they had HIV. As illustrated in the following quotes, participants perceived that people avoided speaking with them.

People treat you differently. People don't talk to you. . . You can see it in people's faces. . . their reaction. -man, age 44

... Some people that I've run into that have known, they have treated me differently, so unless I'm very comfortable with them, I don't bring it up. - man, age 20

Others described the feeling of being treated differently as more subtle.

It's not that anybody ever says anything, it's just kind of a vibe you get. Like, somebody looks at you in a certain way or says certain things that can be taken two different ways, you know. - woman, age 43

When describing experiences of being treated differently, participants often described how feelings of stigma were intensified because HIV is associated with other stigmatized conditions such as being gay or a drug user. As indicated in the first quotation below, one participant described how these co-stigmas can be intensified in rural settings.

It's still considered to be a gay disease. There's a lot of smaller, rural areas and there's obviously an aversion to everything it can represent. You know... contagion, alternative lifestyle, and all that...drug use. -woman, age 51

If you're pos, you got it from sex, that's the highest probability, therefore, you are a slut. Um, therefore, you are queer, you are any number of other things that everybody is but nobody admits. Um, it's about giving other people a reason of power over you, that's what it is. -man, age 33

... you never know how people are going to react. Ok, you know that I am gay... That's one thing you have to deal with. Ok, now then, you have to put HIV + on top of that, it's like are my children 
safe? So I think that you have to deal with one first, then the other. . . It's odd because you don't know if you are being discriminated against if you're gay or if you're HIV+. —man, age 42

\section{Experiences of stigma and discrimination in health care settings}

In addition to their experiences in the community, an aim of this study was to explore participants' personal experiences with stigma and discrimination when seeking or receiving health care services. Of the 16 participants, 11 reported feeling stigmatized or having one or more instances of being judged unfairly, treated with disrespect, or discriminated against when interacting with health care providers. The number of times participants had these experiences varied. For example, one of the key informants indicated that he had not experienced discrimination when getting care from health care providers, with the exception of pharmacies. In contrast, other participants described multiple experiences of discrimination with different providers. The term "health care providers" included a wide range of provider types including physicians, nurses, dentists, pharmacists, and others who people may come in contact with when seeking or obtaining health care services.

The interview data generated three major themes with respect to participants' experiences of discrimination by health care providers: providers behaved like they were afraid of the participants, providers refused or discouraged treatment, and providers treated participants differently than other patients.

Providers behaved like they were afraid of the participants. Some participants reported that providers would not touch them and/or would use what participants considered unnecessary or added protection, as the following quotations illustrate:

Because they won't touch you. They act scared to touch you. They put on gloves right away-just to touch your skin-like they don't know HIV is not spread that way. —woman, age 44

. . and the lady just said, oh, I see you've got this, I'd better go put on my other pair of gloves, I don't think these are quite heavy enough. The rubber gloves she had, she had some thinner ones and she just felt like she should put on heavier rubber gloves, the needle was going to go through those.... and she took my blood pressure and everything and it just felt like she wanted to stand back, not lean over you or anything, like she might pick something up.... I could tell she was uncomfortable treating me.... Anyway, my friends were in the room and they said, she's sure funny, isn't she? I don't think she should be here if she acts like she's scared to hold anybody's arm. My friend could tell, it wasn't just me, they could tell she just felt like she wanted to stay away. They didn't get the idea that she was worried about me being HIV, they just got the idea she felt uncomfortable holding my arm, but I knew what she was doing, kinda like she didn't want it to [get her]. - man, age 58

Well I had one dentist completely refuse to examine me, referred me to another dentist. I had a nurse shake so bad that was going to give me an IV that I kicked her out of my room. I had another nurse that didn't want to do it and another one came with her, those are humiliating.... [A couple questions later] I had a tooth that was very bad. And I went in and I was in a lot of pain, didn't feel well and [the dentist] and she put her gloves on, they set me up, they did X-rays, and she wouldn't even look in my mouth, she wouldn't touch me with her hands, she just looked at the x-ray and said, you'll have to got to [a city], we can't do that here. From what I understand and what I've experienced in my life, usually a dentist will do a physical examination to see what's going on in there. -woman, age 43
Providers refused or discouraged treatment. The last quotation also illustrates the second theme, providers refusing or discouraging treatment. Other participants also described how providers refused to treat them and/or referred them elsewhere for care. For example, one participant said the following about an experience he had with a dermatologist:

He wouldn't treat me once I told him I was HIV+ and I got really mad and told him so. I left and in the elevator the nurse told me that she was sorry for the way I was treated. - man, age 44

Another example is from a participant who describes his experience having an acupuncturist refer him to a different provider:

I'm suspicious that I am, but I could never prove it. I get acupuncture every week, and the first guy I asked for acupuncture, when he found out, you know, I disclosed it to him, because there could be blood, and I figured I owe it to him, he referred me to someone else, ostensibly, because he doesn't deal with my particular problems, asthma, but if that were the case, why did he list asthma in his yellow page ad? . . . my dentist, I wouldn't even bring this up, because I'm really paranoid, but has for the first time ever, stopped calling me to remind me to come in and get my teeth cleaned. And I never told my dentist that I'm pos, but I don't know . . - - man, age 33

As indicated, this participant suspected that his dentist had stopped calling with reminders because of his HIV status. A female participant also described experiences when providers did not keep in contact. Talking about home health care, she shared:

Well, they tell me they're going to get some information and they'll be back, and I never see them again. This has happened so many times, it's ridiculous... . And they don't even call me and say, Well, I've changed my mind, or I'm not going to work that area, or whatever. They just shun me, ignore me, they don't answer my calls. Especially being at home all the time, it's important not to sit and wait. -woman, age 52

Treated differently by providers. The third theme was that participants felt they were treated differently by providers because of their HIV status. These experiences of differential treatment were diverse in nature, but most commonly participants talked about intrusive questioning and rude treatment by providers, as illustrated in the following quotes:

I don't remember what I went there for, I just remember her wanting to know how I got the disease and how long I'd had it. I told her I got it from my husband and she wanted to know if he was bisexual, if he did drugs, it was just a whole bunch of questions that were none of her business, I think it was just more of a curiosity. -woman, age 39

Rude, I don't have any proof that it was because of the medicine I was picking up, but the pharmacist at [name of store and location], I've actually talked to the manager, because he's just a jackass. I don't know if he's that way to everybody, or what. -man, age 31

This woman, she should not be working with human beings or even animals. I wouldn't send my dog to this lady, she is absolutely offensive. Like I said, I don't spend a lot of time on negative stuff, but I can tell you this, I considered filing a grievance against her the last time I went to the emergency room. - woman, age 43

It happens, and I understand it happens, but if you're going to be rude about it, then get the hell out of the health care industry. -woman, age 51

Participants provided other examples of how they had been treated differently by providers due to their HIV status. 
A particularly striking example came from a female participant who described being ignored by providers when she had a baby:

. . . when I had my daughter, that was, I had a hard time with that And my daughter was, she was my fourth child and so I knew what it was like, I had a cesarean, I knew how often they were supposed to check on you and the whole process and I don't think you could have dragged a nurse to my room, seriously, and finally in the middle of the night, I had been pushing the call button I don't know how long, finally a nurse came in and wanted to know what I wanted and what I needed and I was laying in a pool of blood. And I was like, you need to change me, you need to clean me up, I've been sitting here for hours and she did, she was, it was right after shift change, so she was decent, but none of the other nurses had come. —woman, age 39

Another participant indicated he did not feel stigmatized for being HIV-positive, but went on to describe one experience with a nurse:

Well, I don't know, there's a feeling I did have one time at my doctor's office, I had a different nurse for the day, and she said, "Oh, my goodness, I've never seen anybody with that kind of disease, you know you look a lot different than in my textbook" and I felt kind of funny, you know, but what was I supposed to look like? [laughs] She just said like I proved that all kinds of people, and she of course had my medical charts, because she had to take my temperature and all that and she said, "You sure look different than what I had pictured, I didn't know what you would look like." I felt kind of funny, it didn't really bother me, but it was the way she kind of said it. — man, age 58

Another participant distinguished between support staff and other providers. In response to a question asking whether he ever worries that he will need to disclose his HIV status when seeking HIV and AIDS information, he said he worried "only slightly," and went on to explain as follows:

Um, I guess when I encounter that is when I was going to physical therapy or having to be admitted to the emergency room, I always disclosed it, because for them to treat you properly, they have to know. Primarily, it's the support staff, people behind the desk and stuff, you worry about the impression. I've had nurses I interpreted. . . . to be kind of cold and aloof, and who knows why, but, uh, the doctors and nurses are usually, it doesn't bother them, but the support staff. —man, age 31

Some participants also described being treated differently by providers because of stigma associated with other factors such as being gay or prior drug use. For example, one participant described a provider's reaction to her need for methadone to treat pain:

Well, yeah, there was doctor in the emergency room that really pissed me off. He just . . . I mean, I'd tell him everything, and I had a list of everything I'm taking, and everything and tell him everything and he just looked at me like, You just know everything, don't you? And he didn't even treat my problem, um, it was kind of complicated to go into, but I take methadone for pain and methadone is like synthetic heroin, so, what happens when a heroin user drops out. OK, my [insurance] had a lapse in it, and I couldn't get a refill on my prescription, so, um, I had to go and get more, and I couldn't because it was of course a Friday night by then and I'd been fighting trying to get a refill and I couldn't get it, so finally I had to go to the emergency room and get a dose of methadone. You know, that was the only way they could do it. They just looked at me like I was a junkie or something. It was like, no, this is what [insurance coverage] recommended I take, I had no choice in it, but you know, there's the stigma of being a drug addict or something, and I'm not, I'm just a chronic pain patient. -woman, age 42

\section{Emotional and behavioral responses to stigma and discrimination in community settings}

Throughout the interviews participants volunteered how being stigmatized or discriminated against made them feel and react. Emotional responses to stigma were expressed as feelings of anger, rejections of others' thoughts, discouragement, and shame. In addition, participants described internal struggles related to disclosing their HIV status and rationalizing hurtful behaviors. Behavioral responses to stigma included taking action to socially isolate oneself and seeking support through positive activities.

Anger and rejection of others' thoughts. Participants described rejecting feeling stigmatized and others' thoughts about their HIV status.

I just say [expletive]. I don't care. I like me so I don't care what other people think. -man, age 44

I just ignore it really. I don't really do anything . . . I learned not to let it get to me. -woman, age 39

Discouragement. Others described how difficult it is to remain positive and envision a positive future.

I go into a little cocoon. . . Sometimes people say to me, 'boy your eyes look really yellow today', and they don't realize what they are saying. . . . What gets me is what they [think] they know about AIDS. They don't realize that when your T-cells are below 300, um, that is scary, that's it. And they say, well, at least you don't have full blown AIDS. And I feel like saying right now my T-cells are above 300 but the fact is that I don't tell them when I am down to 180, and what I'm living with I have a definite reaction, I get down, I get tired, I can't motivate, so I can't . . . -woman, age 54

It is lonely, even the most well intentioned people are afraid of HIV. I feel sorrow, sadness, grief. I think about wanting a companion to grow old with. I am a sexual being. I think about never having sex with anyone again. - woman, age 43

Shame. When describing how they coped with stigma, participants discussed feeling ashamed. Two participants described it this way:

... I feel ashamed of the selfishness I exhibited in allowing myself to become infected with this, and as a result, my family has to suffer. -woman, age 54

It's just a disease of shame. It's not something people want to talk about or acknowledge, so I choose not to be heard. -woman, age 39

Decisions to disclose. Participants also discussed their struggle to decide whether or not to disclose their HIV status in their communities. They discuss how disclosure decisions weigh on their minds and the disadvantages of disclosing in small communities.

... whenever I am talking to anyone about anything, almost always HIV is on my mind, and so I'm afraid somebody's going to ask me a question that, in order to answer it, I'll have to lie, and so, that makes me feel ashamed, because I try to be an ethical and honorable person. . . . OK in my community, I don't tell anyone. I suspect that my neighbors know that I am gay, but not because I have told them. I would never, disclose my HIV status. - man, age 33

I was kind of leery about letting anybody know when I moved to [city]. It's such a small place, everybody knows everybody, they've lived there all their lives, but I just figure, you know, people got to learn from it, I've got to learn from it, otherwise, what is the sense of going through it. And so far it has been ok. I've had a few comments, 
like, I was told to stay away from you because I might get it. But, they ain't going to get it.... I haven't really had a problem, knock on wood. - woman, age 52

Rationalize hurtful acts. A number of respondents discussed how they coped with feelings of stigma and rationalized hurtful acts concluding that people 'do not know better.'

Me, I probably try to look at the situation first and why that person might be acting that way, rather than . . . . At first I used to cry. I would think, people could be so mean. Then I started looking at the situation and said, well, they don't know the situation and they don't know everything that is going on with me and they've just had a bad day. Now I find myself making more excuses for them than I did in the beginning now that I can deal with my own mortality. —woman, age 51

I try to not be prejudiced against any other person whether it's because it's AIDS or because they're having trouble money-wise, health wise, they're not smart, or whatever it is. I just try to be kind to people. That's what AIDS has done to me. I try to be more caring. -man, age 50

Isolation. Participants talked about physically isolating themselves from others and ending all sexual relationships because of their HIV status. For example:

Well, I don't go anywhere really, I really stick to myself.... -woman, age 54

Do I feel stigmatized? I don't think about it. I think that, like, for example, this is confidential, my sex life ended the moment I found out. I have not been inclined to start it up again for the fear that I might give it to somebody or that I might be rejected or whatever . . - -man, age 33

Seek outside support. Participants also discussed the need to reach out to others for support and engaged in activities to help support positive attitudes, as the following quotations illustrate:

It isolates you. Sometimes you see people that are around and sometimes you see their thoughts. It limits you I guess. I try not to look at it. I' $m$ in a program where we try to care about each other and stuff, we're all trying to save our lives. It's an alcoholic anonymous group. I go to a meeting every day. - man, age 50

Sometimes it is just too much. So, now I just try to pull myself up everyday. I have this emptiness, I listen to a lot of music, I write a lot of poetry, I do a lot of praying. I'm taking guitar lessons now . . . . I am trying to get back into the swing of life and fill my life with other things that will get my mind off of everything so I'm not just 24 hours thinking of how [expletive] up things are. -woman, age, 43

\section{Emotional and behavioral responses to discrimination when seeking health care}

Participants' responses to experiences of discrimination when seeking health care varied. Participants described a range of emotional reactions including feeling funny, being embarrassed, and actively rationalizing responses. Behavioral reactions included walking out on services, calling provider's attention to the fact that their actions were not acceptable, and advocating for their care with providers.

Participant descriptions of both their emotional and behavioral responses are illustrated in the following quotations:

I thought it was kind of funny, it didn't make me aggravated, but it felt kind of funny, I could tell she was uncomfortable treating me. I never did see her again, I always had another nurse after that. - man, age 58
... got extremely embarrassed. There's been times when I've called them on it, I'm not one to keep my mouth shut, I have called them on it. -woman, age 39

I left. I don't need to deal with that - with people who are [expletive] ignorant. — man, age 44

During the course of her interview, one female respondent described emotional as well as behavioral responses to discrimination. For example, at one point, she stated "I felt degraded." At other times, she advocated for herself. For example, when requesting transportation to an urgent care provider, this participant felt that the transportation service was purposefully refusing or delaying timely service, and her response was as follows: "I said I have HIV and I can't always go for 8 hours, I need to get in right away, you need to accommodate me, this is my handicap, you need to accommodate me." When talking about a negative experience with a nurse, she described balancing the need to avoid creating a scene with the need to advocate for herself.

I didn't do anything. What was there to say without causing a huge scene, it would be making a situation that was not pleasant anyway even more unpleasant, you know. I mean, I was embarrassed too, because this person didn't even care that I say they didn't care, they didn't even try to hide it from me, they didn't see me as a human being, they saw me as an HIV patient. That's why it's so important for me to assert, again, I reiterate, I'm somebody's sister, I'm somebody's friend. - woman, age 43

\section{Discussion}

Our findings indicate that people living with HIV in low HIV prevalence areas experience stigma and discrimination in both community and health care settings. In their day-to-day lives, participants described feeling socially isolated and rejected by friends and family. These descriptions highlight the relational nature of stigma and how rejection by loved ones is especially perceived to be damaging. Consistent with prior research, ${ }^{31,32,40}$ participants described experiences of social rejection and how rules of contact were constructed, leaving them feeling fearful, frustrated, hurt and angry. Participants felt as if they were treated differently because of their HIV status, and in some cases feelings of stigma were intensified if a person was also gay or a drug user. The presence of costigmas has also been reported in other literature highlighting the need to better understand the interrelationship between costigmas. ${ }^{41}$ Overall, we found that participants experienced stigma as part of their day to day challenge to negotiate social relationships with friends, family and other members of their community.

In health care settings, participants described specific instances of discrimination including major and minor acts of bias or prejudice. Participants reported experiencing HIV-related stigma in different types of health care facilities (e.g., doctor and dentist offices and hospitals) and from a range of health care personnel (e.g., physicians, nurses, dentists). Stigmatizing behaviors ranged from nuanced looks, subtle questions, actions indicating fear, awkward exchange of words, and refusals to provide care. These findings, taken together with other studies, ${ }^{29-32}$ suggest that the behavior and actions of health care personnel can negatively impact the health care experience of people living with HIV. Future research should examine the effects of HIV-related stigma and discrimination on the quality of health care and whether those 
effects differ for people living in different social contexts (e.g., rural versus urban areas).

Participants described a range of emotional and behavioral responses to stigma and discrimination. Emotional responses included feelings of anger, discouragement and shame. Behavioral responses included a need to protect oneself through isolation from others, daily struggles to decide when and to whom to disclose their seroprevalence status, and a process of rationalizing others' hurtful actions. Participants also described engaging in positive outlets as a coping mechanism including meditation, learning a new instrument and attending groups. Patients also expressed frustration about how to deal with stigmatizing acts in social and health care settings. Some participants responded by speaking out and becoming stronger advocates for themselves. Future research can expand understanding of a wider range of possible responses to HIV-related stigma and discrimination. Studies that determine the prevalence and impact of specific responses could produce information that would be helpful for developing and improving services for people living with HIV. Research suggests that perceived social support from friends can mitigate feelings of stigma. ${ }^{42}$ Additional research on the role of social support, particularly in low prevalence settings, may be beneficial.

Our study found that people living with HIV in rural areas experience stigma and discrimination in ways similar to those described from studies completed in urban settings. ${ }^{30-32} \mathrm{Al}-$ though we cannot compare the frequency or degree of severity of stigma and discrimination, it appears that people living with HIV in low prevalence areas, like their urban counterparts, struggle with social rejection, decisions related to disclosure of their status, and experiences of stigma in health care settings. We also know that stigma and discrimination occur within a context of challenges related to living in rural areas including lack of access to transportation, lack of access to dental care, and limited support from part-time Ryan White case managers. Quantitative research that examines the extent to which the experiences reported in this study are shared by people living with HIV in other low prevalence or rural settings is needed. Studies that compare stigma and discrimination experiences among people living with HIV residing in diverse settings could also improve our understanding of the needs, assets, and barriers to HIV care that exist among participants regardless of how long they have been HIV positive.

Our findings suggest that interventions are needed to mitigate people's experiences with stigma and discrimination in both social and health care settings. Low prevalence and rural contexts will call for unique strategies and innovative approaches. In this sample, coping mechanisms for most participants included individual activities; in only a few cases did participants report participating in support groups. These findings suggest that interventions to address stigma on an intrapersonal level need to be individually tailored. Interventions designed to address negative self-image or personalized stigma could address a range of needs including individual counseling, cognitive behavioral therapy, social support, empowerment, group counseling and support groups. ${ }^{42-44}$ Addressing discrimination or other acts of mistreatment may call for the development of individual skills. HIV patients could benefit from training interventions that build communication and advocacy skills for use in both community and health care settings. ${ }^{43,45}$
These study results also have important implications for the design and delivery of social and health care services. Participants in this study reported both subtle and more blatant manifestations of stigma and discrimination, both of which interfered with patient care. Participants reported that a range of health care personnel including nurses, physicians, dentists, and para-professional staff acted fearful or communicated that they felt negative feelings toward them. Similar findings were reported in a study of rural HIV service professionals which found that medical staff at referral sources stigmatized against rural dual-diagnosis clients. ${ }^{29}$ For people living with HIV, these actions can act as barriers to accessing care and meeting treatment needs. Training is needed that could address these fears and prevent provider reactions and actions, which no matter how subtle or minute, impact the quality of care for people with HIV. Training needs extend beyond main medical personnel and need to include nonclinic personnel including administrative staff and support staff.

Developing stigma-reduction strategies at a community level remains a very difficult challenge. In this study, many participants expressed that their conditions were no different than those suffering from cancer or other terminal conditions. They expressed a need for the public to be better educated about HIV (data not presented). While community interventions to address HIV-related stigma have occurred in urban settings, little work has been done in rural settings to address the problem.

Some limitations of the study need to be mentioned. First, because we used purposeful sampling strategies, our findings lack generalizability. Like most qualitative research, our goal was not to draw conclusions about a larger population; rather, we wanted to gain insight into a set of topics from the perspective of people living with HIV. Another limitation of our sample, however, is that it was smaller than desired. We had hoped to complete a greater number of interviews, so that we could explore differences in themes by subgroups defined by gender, age, and other characteristics. Further, our primary recruitment source was one physician who provides medical care to the majority of people living with HIV in the threecounty area. To increase and diversify the sample, during the project we expanded our recruitment efforts; unfortunately, we were not successful in recruiting participants through other sources within the project's limited timeframe. Even though participants talked about experiences with multiple providers and health care settings, our findings may not capture the experiences and perceptions of people living with HIV who receive care from other providers or who are not in the health care system. Another potential limitation is that the topic of the interview, particularly in a geographic area with relatively low HIV prevalence, may have affected some people's willingness to be interviewed. Having strong opinions (positive or negative) on the study's topic may also have influenced participation. Despite these limitations, this study has enriched our understanding of the multiple ways that stigma and discrimination affects the lives, health care, and well-being of people living HIV in an area with low HIV prevalence.

Although theoretical models of stigma and discrimination exist, $^{35,36}$ understanding of the mechanisms of how social processes may affect people living with HIV's quality of daily life and experiences with the health care system remains 
limited. Research on how stigma and discrimination manifests in low HIV prevalence areas is especially scarce. Findings from this study suggest that HIV stigma impacts the lives of adults living with HIV in low prevalence areas in diverse ways across social settings and in health care contexts, pointing to a need for development of stigma reduction strategies targeted toward people living with HIV, health care personnel, health care institutions, and the broader community.

\section{Acknowledgments}

This research was supported by the pilot grant program of the College of Health and Human Sciences at Oregon State University.

The authors wish to thank the health care providers who assisted with recruitment. They also thank Jennifer Kue, MA, for coordinating fieldwork; and the interviewers and transcriber for their contributions.

\section{Author Disclosure Statement}

No competing financial interests exist.

\section{References}

1. Chesney M, Smith A. Critical delays in HIV testing and care: The potential role of stigma. Am Behav Sci 1999;42:11621174.

2. Rintamaki LS, Wolf MS, Davis TC, Skripkauskas S, Bennett CL. Social stigma and HIV medication adherence. AIDS Patient Care STDs 2006;20:359-368.

3. Bird ST, Bogart LM, Delahanty DL. Health-related correlates of perceived discrimination in HIV care. AIDS Patient Care STDs 2004;18:19-26.

4. Wenger N, Kusseling F, Beck K, Shapiro M. Sexual behavior of individuals infected with human immunodeficiency virus. Arch Intern Med 1994;154:1849-1854.

5. Wight RG. Precursive depression among HIV infected AIDS caregivers over time. Soc Sci Med 2000:51;759-770.

6. Lee R, Kochman A, Sikkema K. Internalized stigma among people living with HIV/AIDS. AIDS Behav 2002;6:309-319.

7. Vanable PA, Carey MP, Blair DC, Littlewood, RA. Impact of HIV-related stigma on health behaviors and psychological adjustment among HIV-positive men and women. AIDS Behav 2006;10:473-482.

8. Miles MS, Holditch-Davis D, Eron J, Black BP, Pedersen C, Harris DA. An HIV self-care symptom management intervention for African American mothers. Nurs Res 2003;52: 350-360.

9. Hall IH, Li J, McKenna MT. HIV in predominantly rural areas of the United States. I Rural Health 2005;21:245-253.

10. Centers for Disease Control and Prevention. HIV/AIDS Surveillance Report. Atlanta, GA: Center for Disease Control, 2008;18.

11. Centers for Disease Control and Prevention. HIV/AIDS Surveillance in Urban and Nonurban Areas (through 2005). www.cdc.gov/hiv/topics/surveillance/resources/slides/ urban-nonurban/index.htm. (Last accessed April 28, 2008).

12. Castaneda D. HIV/AIDS-related services for women and the rural community context. AIDS Care 2000;12:549-565.

13. McKinney M. Variations in rural AIDS epidemiology and service delivery models in the United States. J Rural Health 2002;18:455-466.
14. Berry DE, McKinney MM, McClain M. Rural HIV service networks: Patterns of care and policy issues. AIDS Public Policy J 1996;11:36-46.

15. Preston DB, D'Augelli AR, Kassab CD, Cain RE, Schulze FW, Starks MT. The influence of stigma on the sexual risk behaviors of rural men who have sex with men. AIDS Educ Prev 2004;16:291-303.

16. Williams ML, Bowen AM, Horvath KJ. The social/sexual environment of gay men residing in a rural frontier state: Implications for the development of HIV prevention programs. I Rural Health 2005:21:48-55.

17. Reif S, Golin CE, Smith SR. Barriers to accessing HIV/AIDS care in North Carolina: Rural and urban differences AIDS Care 2005;17:558-565.

18. Stephenson J. Rural HIV/AIDS in the United States. JAMA 2000;248:167-168.

19. Cohn SE, Berk ML, Berry SH, et al. The care of HIV-infected adults in rural areas of the United States. I Acquir Immune Defic Syndr 2001;28:385-392.

20. Martin EG, Pollack HA, Paltel AD. Fact, fiction, and fairness: Resource allocation under the Ryan White CARE Act. Health Aff 2006:25;1103-1112.

21. National Rural Health Association. HIV/AIDS in rural America. Disproportionate impact on minority and multicultural populations. Washington, D.C.: National Rural Health Association, July 2004. www.nrharural.org/advocacy/sub/ issuepapers/HIVAids.pdf (Last accessed April 28, 2008).

22. Heckman BD, Catz SL, Heckman TG, Miller JG, Kalichman SC. Adherence to antiretroviral therapy in rural persons living with HIV disease in the United States. AIDS Care 2004;16:219-230.

23. Probst JC, Moore CG, Glover SH, Samuels ME. Person and place: The compounding effects of race/ethnicity and rurality on health. Am J Public Health 2004;94:1695-1703.

24. Heckman TG, Somlai AM, Kalichman SC, Franzoi SL, Kelly JA. Psychosocial differences between urban and rural people living with HIV/AIDS. J Rural Health 1998;14:138-145.

25. Golin C, Isasi F, Breny Bontempi J, Eng E. Secret pills: HIVPositive patients' experiences taking antiretroviral therapy in North Carolina. AIDS Educ Prev 2002;14:318-329.

26. Bennett ME, Weyant RJ, Simon M. Predictors of dental student's beliefs in the right to refuse treatment to HIV-positive patients. J Dent Educ 1993;57:673-679.

27. Clarke AE. Barriers to general practitioners caring for patients with HIV/AIDS. Fam Pract 1993;10:8-13.

28. Preston DB, Forti EM, Kassab C, Barthalow K. Personal and social determinants of rural nurses' willingness to care for persons with AIDS. Res Nurs Health 2000;23:67-78.

29. Yannessa JF, Reece M, Basta TB. HIV provider perspectives: The impact of stigma on substance abusers living with HIV in a rural area of the United States. AIDS Patient Care STDs 2008;22:669-675.

30. Lekas H, Siegel K, Schrimshaw EW. Continuities and discontinuities in the experiences of felt and enacted stigma among women with HIV/AIDS. Qual Health Res 2006;16:1165-1190.

31. Rintamaki LS, Scott AM, Kosenko KA. Male patient perceptions of HIV stigma in health care contexts. AIDS Patient Care STDs 2007;21:956-969.

32. Sayles JN, Ryan GW, Silver JS, Sarkisian CA, Cunningham WE. Experiences of social stigma and implications for healthcare among a diverse population of HIV positive adults. J Urban Health 2007;84:814-828.

33. Allport GW. The Nature of Prejudice. Garden City, NY: Doubleday, 1953. 
34. Goffman E. Stigma: Notes on the Management of Spoiled Identity. New York: Simon and Schuster, 1963.

35. Stuber J, Meyer I, Link B. Stigma, prejudice, discrimination and health. Soc Sci Med 2008;67:351-357.

36. Herek GM, Mitnick L, Burris S, et al. Workshop Report: AIDS and stigma-A conceptual framework and research agenda. AIDS Public Policy J 1998;13:36-47.

37. National Rural Health Association. Delivering HIV Care in Rural Areas: Best Practice. Washington, D.C.: NRHA https://nrharu.sslcert14.com/pubs/pdf/HIVRuralCare.pdf. (Last accessed April 26, 2008).

38. Henry J Kaiser Family Foundation. HIV/AIDS Policy Fact Sheet-Ryan White Care Program March 2007. www.kff.org/ hivaids/upload/7582_03.pdf. (Last accessed April 26, 2008).

39. Neuendorf KA. The Content Analysis Guidebook. Thousand Oaks: Sage Publications, 2002.

40. Bogart LM, Cowgill BO, Kennedy D, et al. HIV-related stigma among people with HIV and their families: A qualitative analysis. AIDS Behav 2008;12:244-254.

41. Chan KY, Yang Y, Zhang KL, Reidpath DD. Disentangling the stigma of HIV/AIDS from the stigmas of drugs use, commercial sex and commercial blood donation-A factorial survey of medical students in China. BMC Public Health
2007;7:280. http:www.biomedcentral.com/1471-2458/7/280. (Last accessed April 18, 2008).

42. Galvan FH, Maxwell D, Banks D, Bing E. HIV Stigma and social support among African Americans. AIDS Patient Care STDs 2008;22:423-436.

43. Emlet CA. Experiences of stigma in older adults living with HIV/AIDS: A mixed-methods analysis. AIDS Patient Care and STDs 2007; 21:740-752.

44. Heijnders M, Van Der Meij S. The fight against stigma: An overview of stigma-reduction strategies and interventions. Psych, Health \& Medicine 2006;11:353-363.

45. AMA. Speak Up Initiatives. www.jointcommission.org/ PatientSafety/SpeakUp/. (Last accessed August 11, 2008).

Address reprint requests to: Ann P. Zukoski, Dr.P.H., M.P.H.

Department of Public Health

Oregon State University

254 Waldo Hall

Corvallis, OR 97331-6406

E-mail: ann.zukoski@oregonstate.edu 